\title{
Near miss: Almost error or potential adverse event?
}

\author{
Helaine Carneiro Capucho
}

This letter is intended to review the translation used in Brazil for the term 'near miss'. This term is frequently used in Brazilian publications addressing patient safety, especially those concerning medication errors, and is translated as 'almost error'.

The most recent publication of the World Health Organization (WHO) on the taxonomy of patient safety presents nine definitions of 'near miss'. These conceptualize it as an incident with potential to harm the patient and that, for one reason or another, is purposely or by chance intercepted before reaching the patient ${ }^{(1)}$.

According to the WHO publication, this incidence is classified as: incident without harm, incident with harm (adverse event), or near miss ${ }^{(1)}$. Among the incidents related to medication, medication errors and adverse drug reactions stand out ${ }^{(2)}$.

A medication error is an evitable accident that occurs in any stage of the medication process ${ }^{(1,3)}$. An error that occurs in the prescription phase and is intercepted before medication is administered to the patient is currently defined by various Brazilian authors as an 'almost error'. In these cases, the error actually occurred but was intercepted before it reached the patient. It was actually an incident with the potential to harm, that is, a potential adverse event. A potential adverse event is defined by WHO as a severe error or incident with the potential to cause an adverse event, but the event did not occur by chance or because it was intentionally intercepted(1). Hence, a 'near miss' should be understood as a potential adverse event and not as an 'almost error'.

Standardizing patient safety terminology in Brazil is useful and necessary for improving the quality of publications addressing this topic, aiding researchers and professionals in the field to standardize concepts and descriptors, facilitating the search for papers and their citation. Such standardization can be performed through the translation of the WHO patient safety taxonomy into the Portuguese language.

Correspondence:

Helaine Carneiro Capucho

Universidade de São Paulo. Escola de Enfermagem de Ribeirão Preto

Departamento de Enfermagem Geral e Especializada

Programa de Pós-graduação em Enfermagem Fundamental

Av. dos Bandeirantes, 3900

Bairro: Monte Alegre

CEP: 14040-902, Ribeirão Preto, SP, Brasil

E-mail: helainecapucho@yahoo.com.br 


\section{References}

1. World Health Organization. The Conceptual Framework for the International Classification for Patient Safety. Version 1.1. Final Technical Report. Chapter 3. The International Classification for Patient Safety. Key Concepts and Preferred Terms [Internet]. Cidade: WHO; 2009 [cited 2011 Jul 4]. Available from: http://www.who.int/patientsafety/ taxonomy/icps_chapter3.pdf

2. Morimoto T, Gandhi TK, Seger AC, Hsieh TC, Bates DW. Adverse drug events and medication errors: detection and classification methods. Qual Saf Health Care 2004;13:306-314.

3. Committee of Experts on Management of Safety and Quality in Health Care (SP-SQS). Expert Group on Safe Medication Practices. Glossary of terms related to patient and medication safety [Internet]. 2005 [cited 2010 Aug 3]. Available from: http://www.bvs.org.ar/pdf/seguridadpaciente.pdf

Helaine Carneiro Capucho is Pharmaceutical, Risk and Patient Safety Manager, Hospital das Clínicas, Faculdade de Medicina de Ribeirão Preto, Universidade de São Paulo. Doctoral Students in Sciences, Escola de Enfermagem de Ribeirão Preto, Universidade de São Paulo, WHO Collaborating Centre for Nursing Research Development, SP, Brazil. E-mail: helainecapucho@yahoo.com.br. 